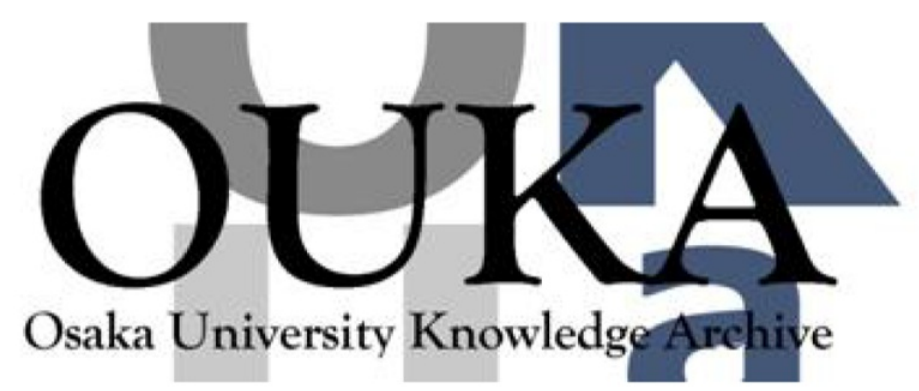

\begin{tabular}{|c|l|}
\hline Title & Plasma Application in Steel Industry in Japan \\
\hline Author(s) & Ushio, Masao \\
\hline Citation & Transactions of JWRI. 21(1) p.9-p. 15 \\
\hline Issue Date & $1992-06$ \\
\hline oaire:version & VoR \\
\hline URL & https://doi.org/10.18910/8207 \\
\hline rights & \\
\hline Note & \\
\hline
\end{tabular}

Osaka University Knowledge Archive : OUKA

https://ir. Library. osaka-u. ac. jp/

Osaka University 


\title{
Plasma Application in Steel Industry in Japan ${ }^{\dagger}$
}

\author{
Masao USHIO*
}

\begin{abstract}
Recent advances are reviewed on several aspect of thermal plasma technology, particularly the works presented in the research group of thermal plasma processing in Iron and Steel Institute of Japan (ISIJ). Included is a brief description of the following fields.

1) Fundamental Studies of high power arc, application of magnetic field to the plasma arc, and thermionic electrode in the plasma torch.

2) Application of high power plasma arc to the heating, melting and refining in industrial and laboratory scales.

3) Production of ultra fine particles of metals, ceramics and their composites by low pressure hydrogen arc.

4) Some fundamental studies relating with plasma synthesis, chemical vapor deposition, and others.
\end{abstract}

KEY WORDS: Termal Plasma, Arc Plasma, Plasma Torch, Plasma Application

\section{Introduction}

The plasma processing of materials is an important, still growing field, which encompasses a wide spectrum of activities, ranging from the production of electronic devices, deposition and coating, to the synthesis of new functional materials and melting-refining of important engineering materials. Reflecting this situation of plasma processing, six or more working groups or research committees have been established in the related engineering and scientific societies, for the past decade in Japan. And JSPC (Japan Symposium on Plasam Chemistry) has also been organized corresponding to ISPC, and has had meetings regularly. The Committee of Thermal Plasma Processing set up in the Iron and Steel Institute of Japan is one of the active research groups, which deals with thermal plasma processing mainly, founded in 1989.

In the following section of the paper, the author briefly describes some of the most recent research activities related with the thermal plasma processing in Japanese steel industries, based mainly on the works reported in the committee. As some of them appear in germinal stage and some are far from the fields of steel production process, a little details are mentioned for them. The contents will cover following fields:

- Fundamentals of thermal plasma, plasma generation

- Heating, melting, refining, dust treatment

$\dagger$ Received on May 6, 1992

* Professor
- Production of metal-ceramics composite fine particles by arc

- Synthesis, deposition, thin film, and others.

\section{Fundamentals of Thermal Plasma}

In this field, Fundamental studies including arc physics, plasma diagnostics, modelling, and plasma torch are described. To investigate the feasibility of utilizing a plasma arc for heating molten steel in a low pressure degassing vessel for secondary refining, the properties of a long plasma arc in a low pressure environment were studied and some preferable features, namely low radiation loss, very good stability, sensitivity of arc voltage to the partial pressure of diatomic gas, were made clear $^{1)}$. In Fig. 1, the effect of pressure on heat balance of plasma arc is shown.

These promising features of the low pressure arc as the heat source have provided a wide range of applications. Preliminary experiment with the combined system of induction skull melting and plasma arc melting was made. A stabel arc was maintained above around 10 Torr in pressure and the $70-90 \%$ of total power dissipated for generation of arc was transferred to the anode material ${ }^{2}$.

With respect to the atmospheric plasma arc, the control of transferred arc attachment to the work by external magnetic field was studied ${ }^{3}$. In Fig. 2, an example of experimental alignment of the magnetic coil and plasma Transactions of JWRI is published by Welding Research Institute of Osak University, Ibaraki, Osaka 567, Japan 

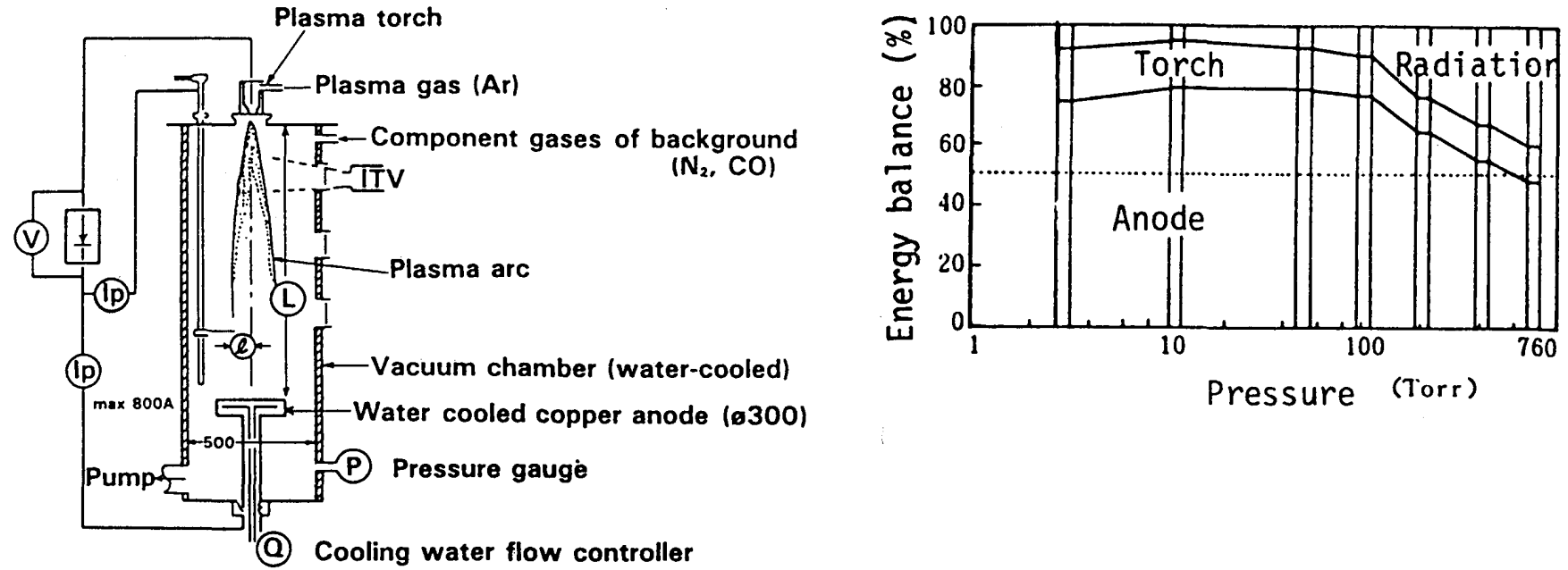

Fig. 1 Low pressure plasma arc and its heat balance ${ }^{1)}$
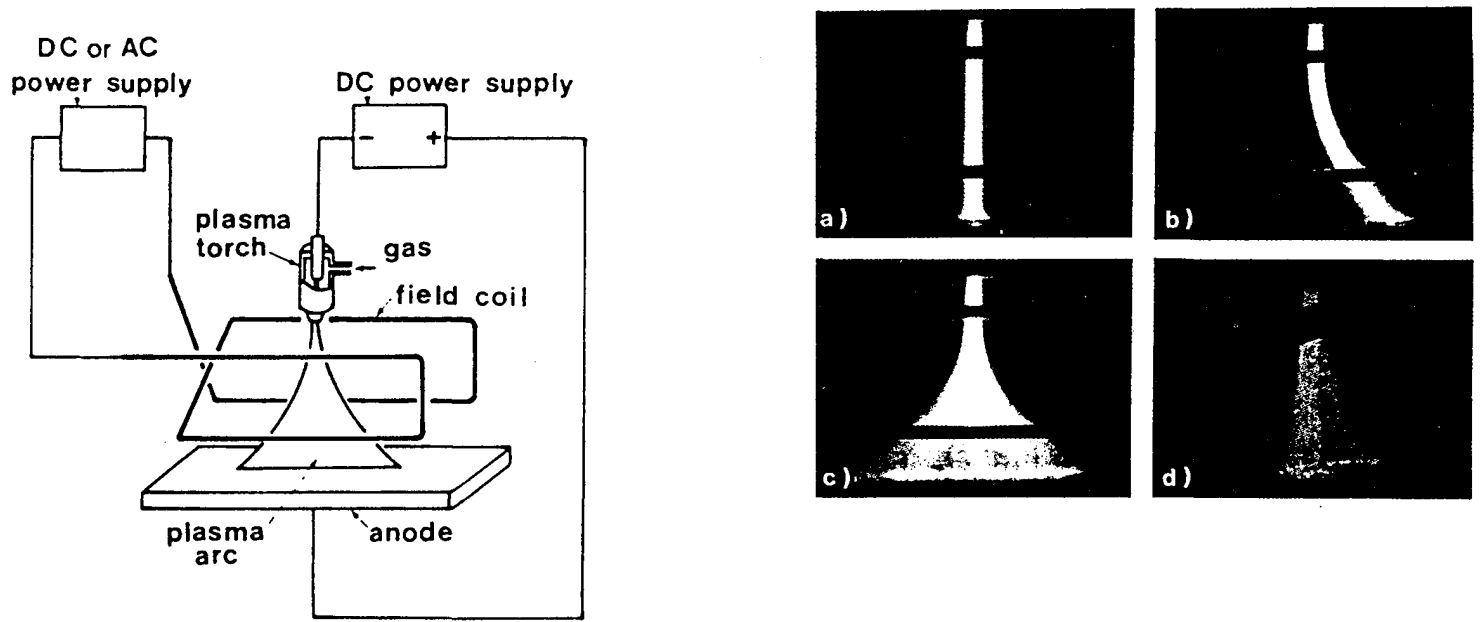

Fig. 2 Allignment of magnetic control of plasma arc configuration ${ }^{3)}$

torch is shown. Through the experiment and its theoretical analysis, the conditions under which a wide and fast weaving of plasma arc column could be obtained, are deduced. And also by the use of the results the condition of parallel set up of plasma arc columns without mutual deflection was presented.

In order to increase the power dissipation in the plasma arc, arc current or electric resistance of the arc should be increased. Increase in arc current is not preferable from the view point of economy. NKK Corp. has been developing a unique plasma arc torch which generates turbulent plasma arc with a good reproducibility ${ }^{4}$. A vortex flow of gas and a trapezoidal shape of the cathode provide the condition under which an unstable arc mode is excited at above a critical arc current. This is a kind of MHD instability whose occurrence is assisted by the movement of cathode spot, as shown in Fig. 3. In this unstable, turbulent plasma arc, the arc voltage is rather higher than that of the stable arc, because of the cooling of arc column due to fast movement. This plasma arc is much interesting and seems to be expectable in providing a wide application for heating system. I Fig. 4, a comparison of the arc voltage of the turbulent plasma arc with that of the stable plasma arc is shown.

The most serious problem of solid electrode plasma torch is the electrode erosion. Particularly in case of high power plasma torch equipped with thermionic cathode like tungsten, insufficient life time of the cathode has been the most essential and urgent issue to be solved. Tungsten electrodes activated with $\mathrm{La}_{2} \mathrm{O}_{3}, \mathrm{Y}_{2} \mathrm{O}_{3}$ and $\mathrm{Ce}_{2} \mathrm{O}_{3}$ respectively and that with combined additives of those oxides have a superior properties in durability and stability compared with thoriated tungsten. The reason is in the well balance betweena the oxide consumption from cathode surface which provide the low work function, and the feed of oxide from inside the electrode to the surface. This was 

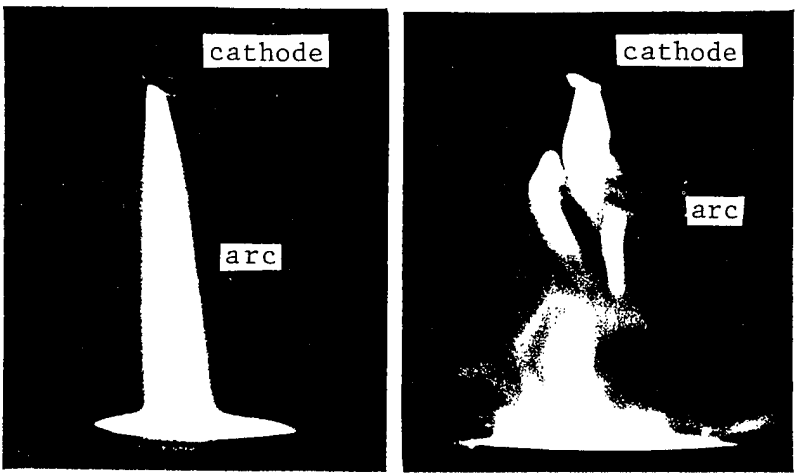

Fig. 3 Photographs of stable and unstable plasma $\operatorname{arcs}^{4)}$

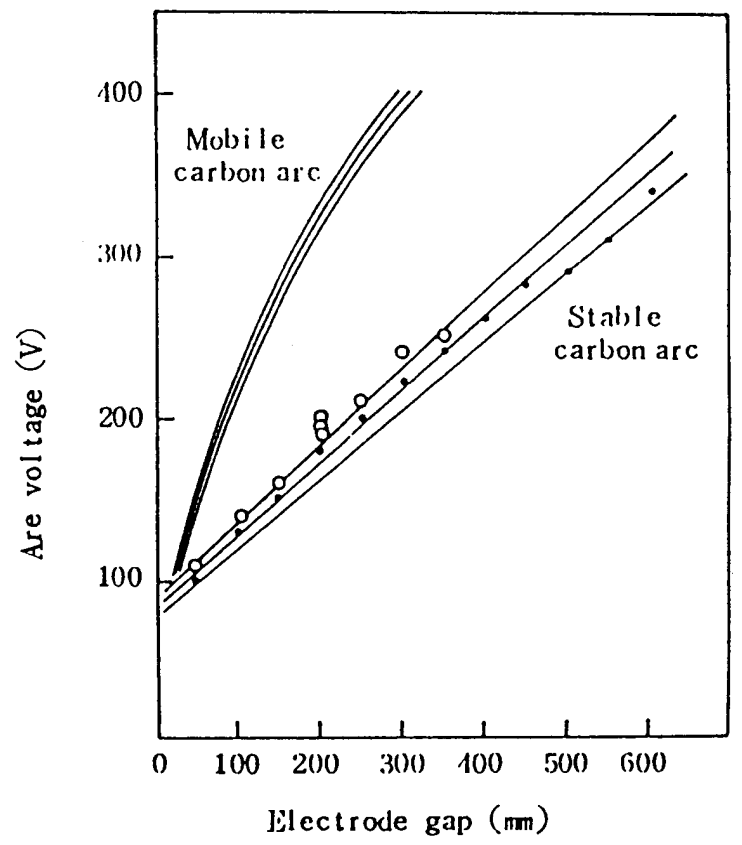

Fig. 4 Comparison between arc voltage of unstable arc and that of stable one ${ }^{4}$

precisely studied at Osaka University ${ }^{5-7)}$ and some additional tests of electrode erosion were made by O.U. and CRIEPI $^{8}$. The most influencing factors to the electrode erosion seem to be the heat flux density and the oxygen in working gas. If the torch was used in the sufficiently inert atmosphere, these tungsten cathodes have a rather long life. Because the input heat flux to the thermionic cathode could be controllable by proper arrangement of heat sink just near the cathode even the mechanism of self-sustaining discharge holds and the heat input to the cathode is determined by arc itself. Thus, the excess heat input should occur in case that it is used as anode and it is too small.

The tungsten electrode is severely eroded under the existence of oxidizing gas even if it were of a very small amount. Therefore, the most important in the high power plasma torch is the configuration designing of torch structure. Especially the behavior of gas flow near the electrode shoud be taken into consideration to protect the tungsten from oxidizing gas. And also the temperature field in the electrode must be adjusted suitably. In Fig. 5 and Fig. 6, some results of erosion test are shown.

Nippon Steel Corp. has been studying to develop a 10 $\mathrm{kA}$ class high power hot cathode transferred-type plasma torch. In Fig. 7, an example of plasma torch under developing is illustrated ${ }^{9)}$.

\section{Heating, Melting and Refining}

Since the application of plasma arc to tundish heating system in Hirohata Works of Nippon Steel Corp. have brought about satisfactory results ${ }^{10)}$, almost of iron and steel makers in Japan have been introduced the high power plasma arc system for similar tundish heating. Major advantage of plasma arc system is that it eliminates any need for modification or reinforcement of the tundish when installed. The most recent data published are on the DC transferred type system developed at Keihin Works of NKK Corp. (1.4 MW max., $7 \mathrm{kA}$ and $200 \mathrm{~V}$, single torch) and on the $\mathrm{AC}$ transferred/non-transferred type system at

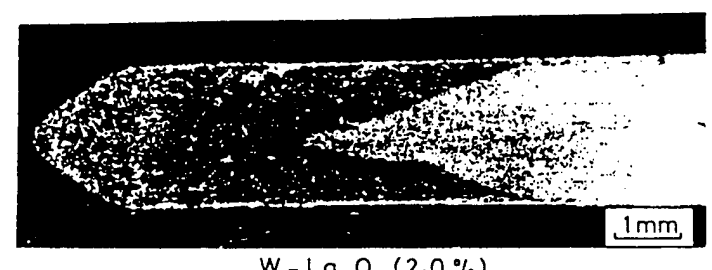

$$
W-\mathrm{La}_{2} \mathrm{O}_{3}(2.0 \%)
$$

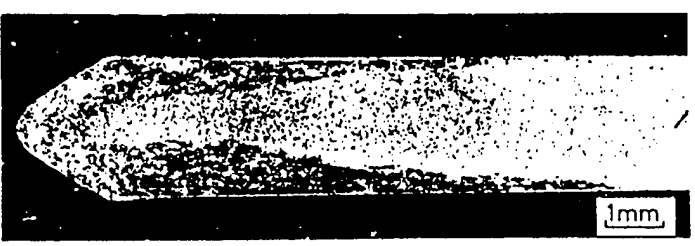

W-La $\mathrm{O}_{3}: 0.6 \%-\mathrm{CeO}_{2}: 0.8 \%-\mathrm{Y}_{2} \mathrm{O}_{3}: 0.6 \%$

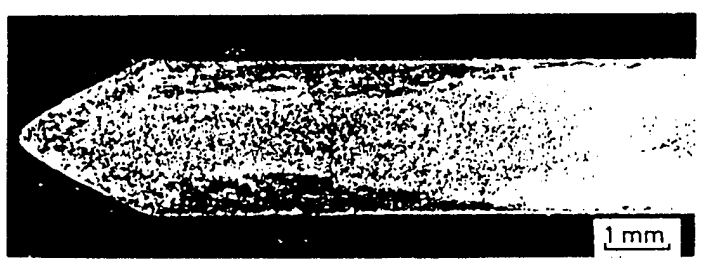

$W-\mathrm{La}_{2} \mathrm{O}_{3}: 0.4 \%-\mathrm{CeO}_{2}: 0.4 \%-\mathrm{Y}_{2} \mathrm{O}_{3}: 1.2 \%$

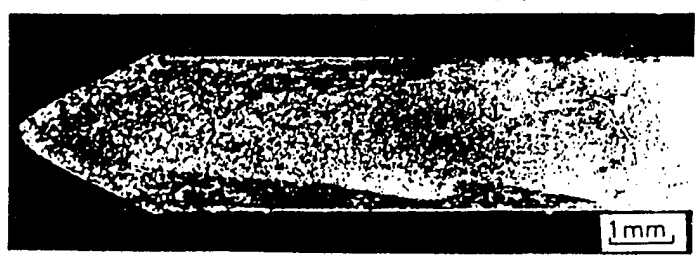

$W-\mathrm{La}_{2} \mathrm{O}_{3}: 0.4 \%-\mathrm{CeO}_{2}: 1.2 \%-\mathrm{Y}_{2} \mathrm{O}_{3}: 0.4 \%$

Fig. 5 Distributions of oxide remaind inside tungsten electrode after $10 \mathrm{Hrs} 180 \mathrm{~A}$ arcing with $2.4 \mathrm{~mm}$ in diameter ${ }^{6)}$ 


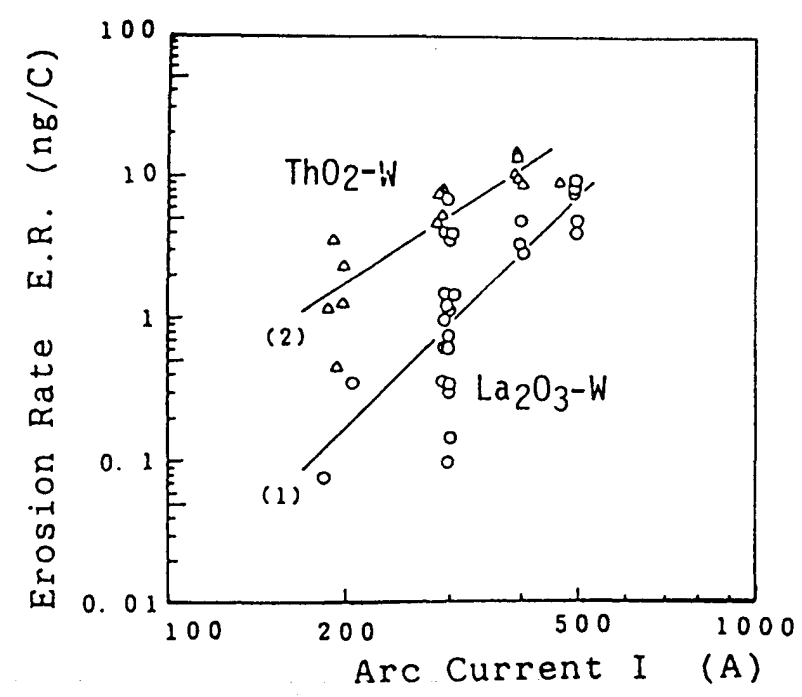

Fig. 6 Comparison of erosion rates of $\mathrm{La}_{2} \mathrm{O}_{3}-\mathrm{W}$ and $\mathrm{Tho}_{2}-\mathrm{W}$ elecrodes $^{8)}$

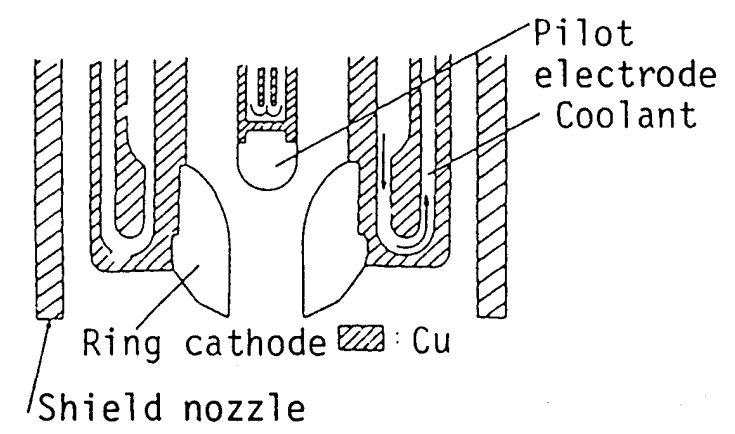

Fig. 7 An example of plasma torch structure under developing ${ }^{9}$

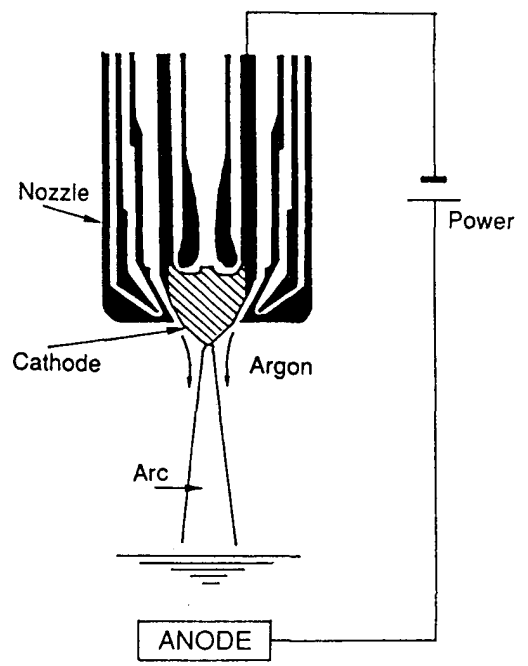

Fig. 8 Schematic illustration of DC torch ${ }^{10)}$

Kakogawa Works of Kobe Steel Ltd. (2.4 MW max., 7.5 $\mathrm{kA}$ and $350 \mathrm{~V}, 2$ torches, single phase).

NKK developed the system ${ }^{11}$ based on the date obtained with pilot plant eqipped a $200 \mathrm{~kW}$ ( $\mathrm{kA}$ and $100 \mathrm{~V}$ ) DC plasma torch. To determine the specification of the system, comparison of experimental heat flow with computer simulation, and measurements of arc characteristics and heat efficiency were made very carefully. Fig. 8 shows the cross sectional view of plasma torch head.

As increase in arc current, a leak current circuit develops between the cathode/nozzle and the nozzle/ground, respectively. An abnormal increase in the leak current, generates another arc (called "Double are") between the surface of the nozzle and the surface of the chamber wall. These double arc strikes directly against the orifice of nozzle tip and melts it. To prevent the generation of the double arc, out side surface of the nozzle was coated with electrical insulation. The effect of this coating is shown in voltage waveforms in Fig. 9, in which the fluctuations of voltage are minimized. In this system the $80 \%$ in heating efficiency was obtained without slag covering, and by the use of feedback control of electric power the temperature deviation within $\pm 1^{\circ} \mathrm{C}$ was obtainable.

AC plasma heating system has a considerable advantage that it needs not counter electrode in the tundish, though it needs a pair of torch at least. Kobe Steel Ltd. has developed a tundish heating system using the Krupp AC Plasma torch $^{12)}$. Heating efficiency is not so high compared with DC system, but it will be increased by surface coating of torch with insulating materials (Fig. 10). Successful results were obtained in the operation as shown in Fig. 11. The problem of this system is the electrode erosion. High heat input to the electrode when it works as the anode, seems to be a cause for the consumption of oxide from tungsten electrode, which may accelerate the temperature increase of tungsten electrode and consequently result in the heavy thermal loading to the electrode.

These many applications of plasma arc to the tundish heating brought about the improvement in the quality of castings and the cost reduction in converter refaractories, because of lower tapping temperature in the converter. However, research needs still remain in the design problem of plasma torch including electrode.

Some basic studies related with refining process have been reported. Partticylarly spectroscopic study of the near-boundary plasma between hydrogen arc and molten metal anode is much interesting (Fig. 12) ${ }^{13}$. However, the effort to make clear the mechanism of physical and chemical phenomena occurring at the anode spot, such as the evaporation of particular chemical species, the abnormal gas absorption into the molten metal, has not yet achieved satisfactory results. This is due to that the thermodynamic state of the boundary layer is far from the equilibrium, the thickness of the layer is too narrow to obtain the sufficient space resolution and light emission intensity.

$\mathrm{H}_{2}$-Ar plasma arc melting, using a gas mixture of hydrogen and argon as working gas, has been recognized to be 

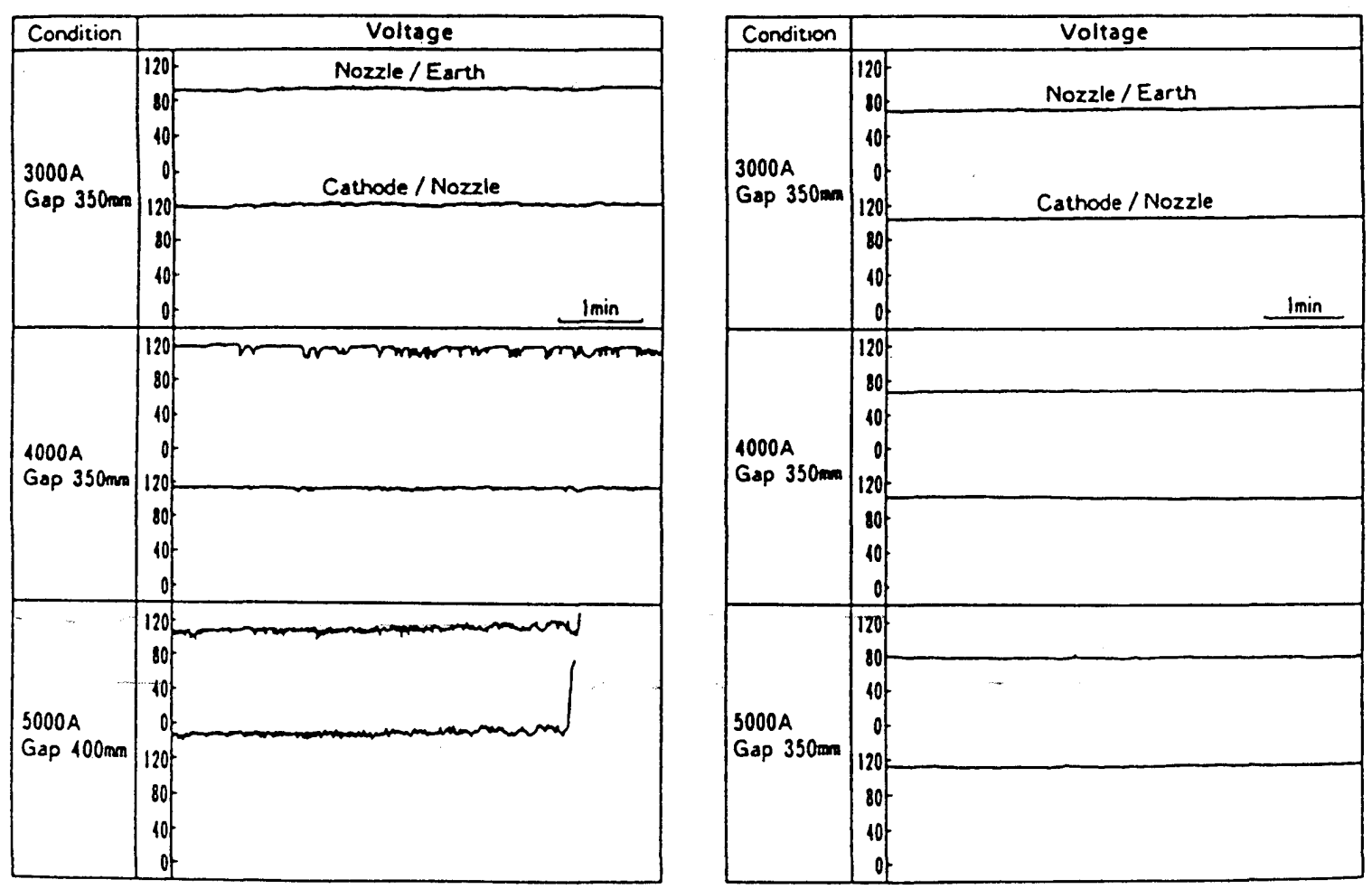

Fig. 9 Effect of insulation coating on the nozzle surface on voltage ${ }^{10}$ )

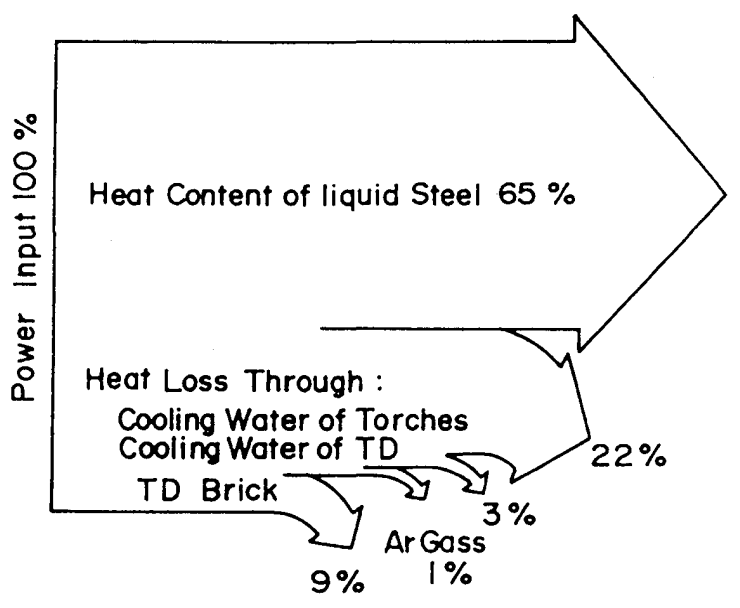

Fig. 10 Heat balance Kobe Steel tundish heating system ${ }^{11)}$

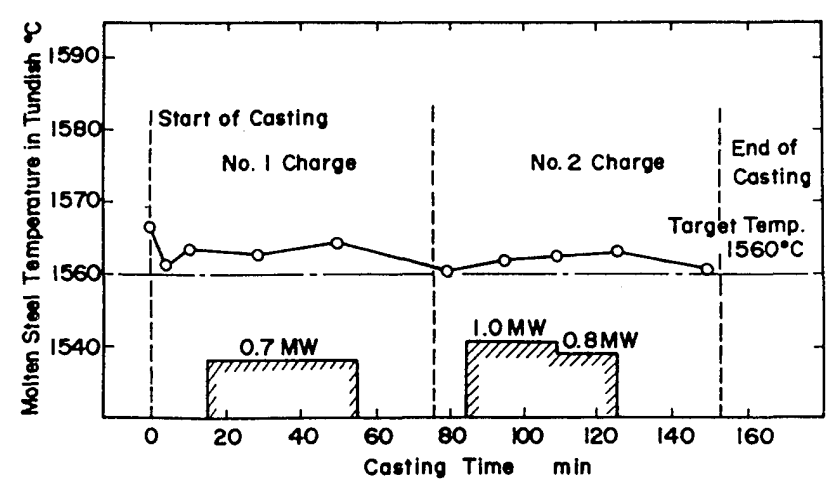

Fig. 11 Molten steel temp. with tundish heating ${ }^{11)}$

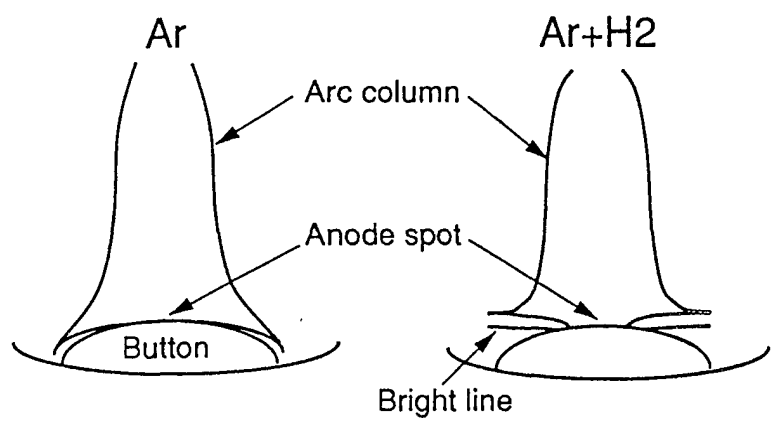

Fig. 12 Schematic illustration of difference in arc boudary appearance of $\mathrm{H}_{2}-\mathrm{Ar} \operatorname{arc}^{13)}$

available for refining various metals. In Sumitomo Metal Industries, a basic research on the plasma arc refining process has been made continuously using $50 \mathrm{~kW} \mathrm{DC}$ plasma arc furnace ${ }^{14.15)}$. Removal of copper and tin in molten steel was investigated and their degree was promoted by applying both $\mathrm{H}_{2}$-Ar plasma and Ar plasma even at $10^{5} \mathrm{~Pa}$ in pressure. The degree of removal of these elements were much greater at reduced pressure and at higher gydrogen contents in the plasma gas. The 90 and $60 \%$ in maximum degrees of removal of $\mathrm{Cu}$ and $\mathrm{Sn}$ respectively were obtained in 2 hours treatment.

Fundamental studies about the mechanism of effective plasma arc refining of metals are made mainly in the universities. These are removal of boron in metallurgical silicon by $\mathrm{Ar}-\mathrm{O}_{2} / \mathrm{CO}_{2}(<1 \%)$ transferred plasma $\operatorname{arc}^{16)}$, 


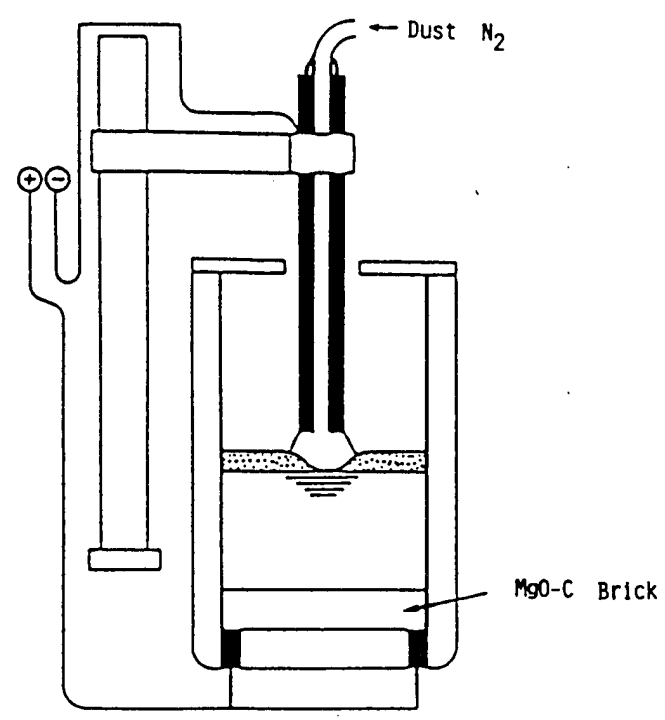

Fig. 13 Hollow cathode DC arc furnace for dust treatment ${ }^{23}$ )

reaction rate of decarburization of molten iron by $\mathrm{Ar}-\mathrm{CO}_{2}$ (5\%) plasma ${ }^{17}$, production of pure tantalum by a combination process of carbon reduction smelting and hydrogen plasma arc melting-refining ${ }^{18)}$, and so on.

With respect to the melting of titanium alloy, small scale and precise experiments on the temperature determination of the anode spot formed on the molten metal surface and the effect of gas composition and metal vapor on the electrical characteristics of plasma arc were carried out ${ }^{19.20}$. However, the effect of metal vapor on arc characteristics is not clear yet.

Kawasaki Steel Corp. has developed a dust treatment system using a hollow graphite cathode DC arc. This system makes it possible to recycle the dust generated in stainless steel production. Yields of $\mathrm{Cr}$ and $\mathrm{Ni}$ were more than 92 and $98 \%$ respectively when the dust was blown through a hollow cathode on to the metal bath. These yields are higher than those when dust is recycled directly into the top and bottom blown converter without agglomeration. In Fig. 13, the furnace is schematically shown ${ }^{21)}$.

A pilot plant of plasma pyrolysis of the wastes generated by the citizens. The prospect of waste management with plasma are heater seems to be promising from the technical point, but some economical problems are still remained ${ }^{22)}$

\section{Production of Ultra Fine Particle}

Ultra fine particle of pure metals, some alloys like Fe-Ni, $\mathrm{Fe}-\mathrm{Cu}$ and $\mathrm{Fe}-\mathrm{Si}$, and composites of Fe-TiN, Ni-TiN and Co-TiN systems were produced by arc melting, vaporization and deposition of iron alloys or binary $\mathrm{Fe}-\mathrm{Ti}, \mathrm{Ni}-\mathrm{Ti}$ and Co-Ti alloys in $\mathrm{H}_{2}(50 \%)-\mathrm{Ar}(50 \%)$ atmosphere at 0.1 $\mathrm{MPa}$. Very active research group of NRIM and Dr. M. Uda
(Nisshin Steel Co. Ltd.) have a strong interest in extending their "hydrogen plasma-metal" reaction to the generation of a wide range of composite materials and analyzing the generation mechanism ${ }^{2324)}$. This research might be a milestone to the generation of new functional materials. Details of their work are described in referenced papers.

\section{Plasma Synthesis, Thin Films and Coating}

Numerous works of thin film production with the low pressure plasma are reported in the various meetings of electronics and applied physics. However the application of thermal plasma to the related research fields is very few. Major reason is the thermal plasma makes us suppose difficult to control the reactive field suitably. Nevertheless, the promising features of thermal plasma processing, namely, the inflight process, which could be utilize the thermal field and flow field in combination with the reactive field, have been extended application field gradually.

The application of thermal plasma to the chemical vapor deposition of diamong film is studying fundamentally in many laboratories ${ }^{25)}$. The nucleation mechanism including the effect of seed addition in a plasma spouted/fluidized bed has also been studying continuously ${ }^{26)}$.

Prof. T. Yoshida and his group has actively developed various kind of thermal plasma process in this field which include the development of hybrid plasma torch for inflight plasma processing, development of thermal plasma flash evaporation process, and so on ${ }^{27)}$. Recently, some miscellaneous fine particles are synthesized by the use of hybrid plasma torch reactor, such as rare-earth alloys like $\mathrm{SmCO}_{5},{ }^{28)}$ nanometer-scaled graphite lamellae, ${ }^{29)}$. $\mathrm{Si}_{3} \mathrm{~N}_{4}$ and $\mathrm{Si}_{3} \mathrm{~N}_{4}-\mathrm{SiC}$ composite, ${ }^{30)}$ and High-Tc superconduction films ${ }^{31)}$.

\section{Conclusions}

Recent research activities of steel industries in Japan on the thermal plasma application to materials processing were reviewed briefly. Thermal plasma spraying, welding, plasma cutting, are eliminated for the limitations of space. Our knowledge of the thermal plasma processing have been improved somewhat, and there are still important areas leaving much more works. Some of them could be identified brieflyas follows:

- Deep understanding of plasma arc and electrode

- Developing durable electrode even in the use in oxidizing atmosphere.

- Physics and chemistry in the boundary layer between plasma and work, particularly at the anode spot.

Obviously above problems are most basic and difficult, but necessary to be solved. 


\section{Reference}

1) T. Kuwabara et al., J. The Iron ans Steel Inst, Vol. 72, No. 5 (1986) s720, (in Japanese).

2) M. Hattori and N. Kitamura. Doc. Research Committee of Thermal Plasm Processing, ISIJ, TP6-3 (1991), (in Japanese).

3) K. Takeda, J. High Temp. Soc, Vol. 16 (1990) P. 357, (in Japanese).

4) N. Ao, in "Electromagnetic Processing of Materials" Nishiyama-Kinen Gijutsu-koza, ISIJ, Vol. 129 \& 130 (1989) p. 253, (in Japanese).

5) A. A. Sadek, M. Ushio, F. Matsuda, Metallurgical Trans. A, Vol. 21 A (1990) p. 3221.

6) M. Ushio, A. A. Sadek, F. Matsuda, Plasma Chem. \& Plasma Processing, Vol. 11 (1991) p. 81.

7) M. Ushio et al., Proc. Technical Conf. Plasma for Industry and Environment, Paper 6.3, BNCE, U. K. (1990).

8) T. Amakawa et al., ibid. paper 6.4, BNCE, U. K. (1990).

9) N. Hirotsu et al., CAMP-ISIJ, Vol. 4 (1991) 702. (in Japanese)

10) M. Fukuyama et al., Proc. 8th ISPC, SI-5 (1987) p.2247.

11) M. Mizushima et al., Proc. Technical Conf. Plasma for Industry and Environment, Paper 4.3, BNCE, U. K. (1990).

12) M. Shimizu et al., ibid. Paper 4.2, BNCE, U. K. (1990).

13) S. Onishi et al., CAMP-ISIJ. Vol. 2 (1989) 1345, (in Japanese).

14) T. Matsuo, J of ISIJ, Vol. 75 (1989) p. 82, (in Japanes).

15) T. Matsuo et al., Doc. Research Committee of Thermal Plasma Processing, ISIJ, TP4-5 (1990), (in Japanese).

16) K. Suzuki et al., CAMP-ISIJ, Vol. 1 (1989) 1346, (in
Japanese).

17) K. Nagata et al., CAMP-ISIJ, Vol. 1 (1988) 1391, (in Japanese).

18) K. Mimura and M. Nanjo, J. Japan Inst. Metals, Vol. 52 (1988) p. 843, (in Japanese).

19) A. Tomita et al., CAMP-ISIJ, Vol. 3 (1990) 317, (in Japanese).

20) T. Kusamichi et al., Doc. Research Committee of Thermal Plasma Processing, ISIJ, TP5-4 (1990), (in Japanese).

21) Y. Kishimoto et al., Proc. Technical Conf. Plasma for Industry and Environment, Paper 2.4, BNCE, U. K. (1990).

22) M. Omori, Doc. Research Committee of Thermal Plasma Processing, ISIJ, TP 6-2, (1991), (in Japanese).

23) S. Ohno et al., J. Japan Inst. Metals, Vol. 53 (1989) P.936, (in Japanese).

24) S. Ohno and M. Uda, J. Japan Inst. Metals, Vol. 53 (1989) p. 946, (in Japanese)

25) S. Matsumoto, Doc. Research Committee of Thermal Plasma Processing, ISIJ, TP2-1 (1989), (in Japanese).

26) M. Horio et al., Proc. 2nd World Cong. Particle Technology. Kyoto, Japan (1990).

27) T. Yoshida, Materials Transactions, JIM, Vol. 31 (1990) p. 1.

28) M. Sugasawa et al., CAMP-ISIJ, Vol. 4 (1991) 699, (in Japanese).

29) K. Yoshie et al., CAMP-ISIJ, Vol. 4 (1991) 700, (in Japanese).

30) H. J. Lee et al., CAMP-ISIJ, Vol. 3 (1990) 322, (in Japanese).

31) K. Terashima et al., CAMP-ISIJ, Vol. 3 (1990) 324, (in Japanese). 